\title{
Operation of a Blast Furnace with Self-Fluxing Sinter*
}

\author{
By Keiji Tsujihata,** Makoto Inoue,** \\ Naoto Nakamura,** Masakazu Yoshinaga** \\ and Koji Yasuda**
}

This paper describes the experiments on the blast furnace operation by use of lime-sinter at Kukioka No. 2 blast furnace of Yawata Iron \& Steel Company from June 1958 to March 1959.

By $100 \%$ self-fluxing sinter burden, a high iron productivity over 0.044 ton per day per cubic ft. of inner volume and the lowest coke rate of 1036 lbs. per ton iron were obtained.

This presentation will discuss the effects of the lime-sinter burden on the operation of the blast furnace.

\section{Operation and Results}

Kukioka No. 2 blast furnace has 31,060 cubic ft. of inner volume (defined by the Iron \& Steel Institute of Japan as the volume from the stockline to the bottom) and $23 \mathrm{ft}$. of hearth diameter. The sinter ratio in burdens was increased gradually from June 1958 and $100 \%$ sinter burden was used from Nov. 1958 to March 1959. During this period the limestone content in the sinter-mix was changed to 0,5 and 10 per cent respectively. Asinter is the sinter of 10 per cent limestone in sinter-mix, B-sinter is of 5 per cent limestone and C-sinter is of no limestone. The schedule of operation, characteristics of the lime sinter, raw materials and operating results are shown in Table I-IV.

Table I. The schedule of the experimental operation

\begin{tabular}{|c|c|c|c|c|c|c|c|c|c|c|}
\hline Year & & & & 1958 & & & & & 1959 & \\
\hline Month & Jun. & Jul. & Aug. & Sep. & Oct. & Nov. & Dec. & Jan. & Feb. & Mar. \\
\hline Limestone in sinter-mix per cent & 5 & 10 & 10 & 10 & 10 & 10 & 10 & 5 & 5 & 0 \\
\hline Sinter ratio in burdens per cent & 40 & 40 & 60 & 80 & 80 & 100 & 100 & 100 & 100 & 100 \\
\hline
\end{tabular}

Table II. The quality of sinter

\begin{tabular}{|c|c|c|c|c|c|c|c|c|c|c|c|}
\hline \multicolumn{2}{|c|}{ Year } & \multicolumn{7}{|c|}{1958} & \multicolumn{3}{|c|}{1959} \\
\hline \multicolumn{2}{|c|}{ Month } & Jun. & Jul. & Aug. & Sep. & Oct. & Nov. & Dec. & Jan. & Feb. & Mar. \\
\hline Fe content & per cent & 56.64 & 54.33 & 54.18 & 55.05 & 54.60 & 55.8 & 55.3 & 57.0 & 57.4 & 58.3 \\
\hline Sulphur content & per cent & 0.03 & 0.06 & 0.11 & 0.07 & 0.08 & 0.03 & 0.04 & 0.03 & 0.03 & 0.03 \\
\hline $\mathrm{CaO} \mathrm{SiO}_{2}$ ratio & & 0.68 & 1.42 & 1.27 & 1.21 & 1.22 & 1.41 & 1.36 & 0.85 & 0.82 & 0.50 \\
\hline Degree of oxidation & per cent & 92.98 & 93.29 & 92.31 & 92.59 & 93.53 & 93.55 & 94.21 & 93.27 & 94.08 & 93.10 \\
\hline Shatter test (index p & ent $+15 \mathrm{~mm}$ & 73 & 72 & 78 & 78 & 79 & 77 & 81 & 84 & 82 & 82 \\
\hline
\end{tabular}

Table III. Raw materials used

(Unit: lbs per ton iron)

\begin{tabular}{|c|c|c|c|c|c|c|c|c|c|c|c|}
\hline \multirow{2}{*}{\multicolumn{2}{|c|}{$\begin{array}{c}\text { Year } \\
\text { Month }\end{array}$}} & \multicolumn{6}{|c|}{1958} & \multirow[b]{2}{*}{ Dec. } & \multicolumn{3}{|c|}{1959} \\
\hline & & Jun. & Jul. & Aug. & Sep. & Oct. & Nov. & & Jan. & Feb. & Mar. \\
\hline \multirow{7}{*}{ Iron ore } & Sintered ore & 1292 & 1324 & 1966 & 2708 & 2654 & 3138 & 3320 & 3208 & 3226 & 3164 \\
\hline & Korean ore & 322 & 352 & 382 & 356 & 322 & 0 & 0 & 0 & 0 & 0 \\
\hline & Dungun washed & 444 & 448 & 436 & 0 & 0 & 0 & 0 & 0 & 0 & 0 \\
\hline & Dungun & 218 & 216 & 208 & 226 & $\begin{array}{l}\text { Srimedan } \\
260\end{array}$ & 0 & 0 & 0 & 0 & 0 \\
\hline & Goa & 812 & 818 & 170 & 0 & 0 & 0 & 0 & 0 & 0 & 0 \\
\hline & Others & 68 & 68 & 66 & 64 & 60 & 0 & 0 & 0 & 0 & 0 \\
\hline & Total & 3156 & 3230 & 3230 & 3352 & 3296 & 3138 & 3320 & 3208 & 3226 & 3164 \\
\hline \multicolumn{2}{|c|}{ Open hearth furnace slag } & 228 & 230 & 220 & 160 & 116 & 110 & 116 & 142 & 116 & 88 \\
\hline \multicolumn{2}{|c|}{ Limestone } & 238 & 278 & 238 & 152 & 188 & 0 & 2 & 244 & 238 & 382 \\
\hline \multicolumn{2}{|l|}{ Metallics } & 0 & 0 & 0 & 0 & 0 & 94 & 0 & 0 & 0 & 0 \\
\hline \multicolumn{2}{|l|}{ Coke } & 1290 & 1300 & 1256 & 1248 & 1186 & 1036 & 1096 & 1142 & 1126 & 1182 \\
\hline
\end{tabular}

* Lecture delivered before the 57 th Grand Lecture Meeting, April 1959 in Tokyo.

Tetsu-to-Hagané (Journal, Iron \& Steel Institute, Japan) Vol. 47, No. 5, pp. 539-548

* Pig Iron Making Department, Yawata Iron \& Steel Co., Ltd. 
Table IV. Operation results

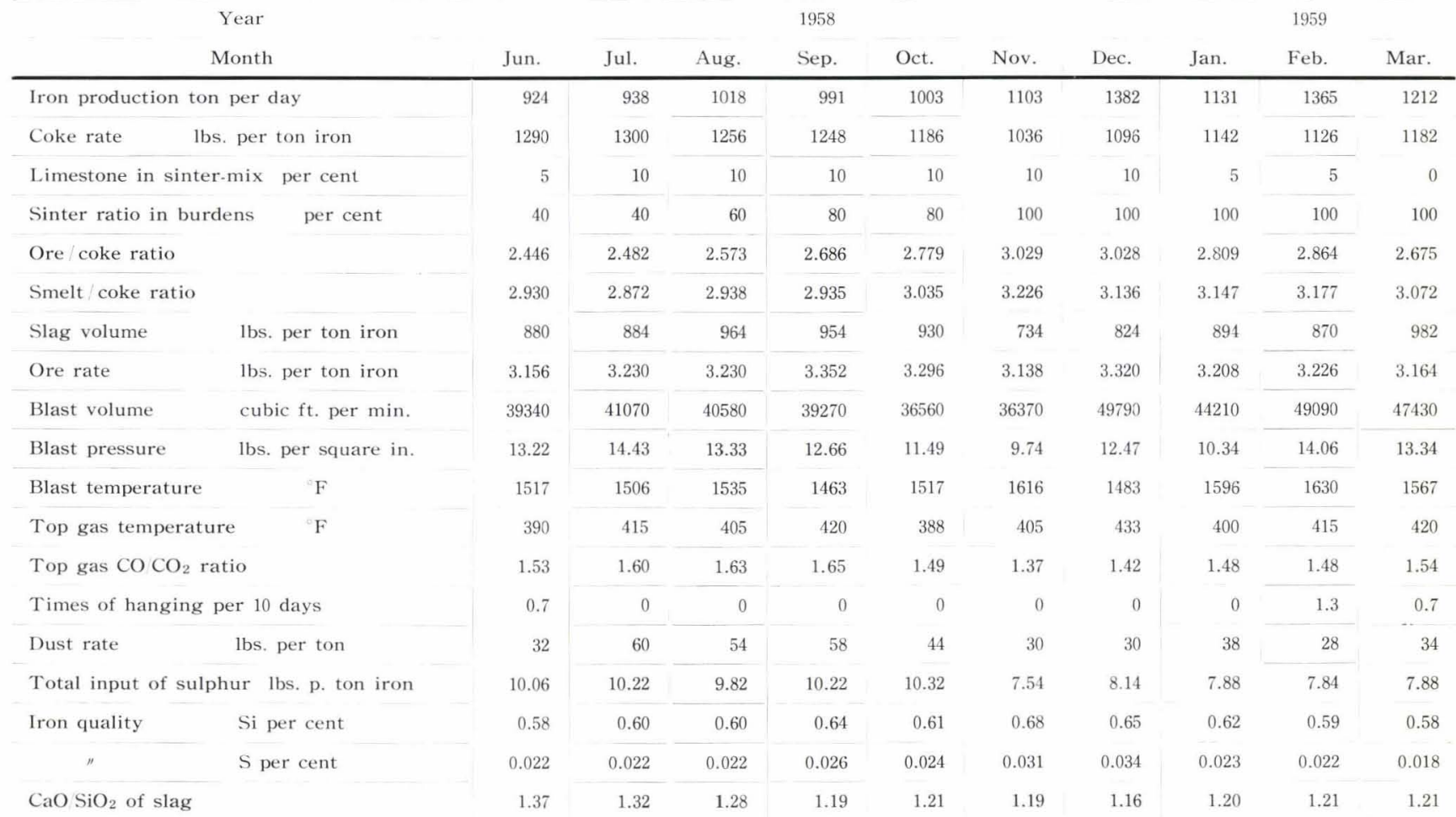

\section{Discussion}

\section{Iron Production}

In December 1958 with 100 per cent A-sinter burden and February 1959 with 100 per cent Bsinter, the authors tried experimental operations to research the maximum iron production without irregular conditions such as slippings and hangings, and obtained 1300 ton iron per day and 0.044 ton iron per day per cubic ft. of inner volume. In December 1958 using A-sinter, the iron production reached 1300 tons per day smoothly without any trouble but more iron production was impossible due to the limitation of the iron casting practice. On the other hand, in February 1959 using B-sinter, the blast pressure was raised abnormally as the blast volume was increased, and finally some hangings were caused and the iron production was restricted.

The iron production is increased by increase of the blast volume. If the permeability of the stock column is low, the blast pressure rises steeply as the blast volume is increased and finally irregular descending of charge is caused.

On the pressure drop in the blast furnace W.O. Philbrook gives the following equation:

$$
\Delta P=f \times G^{2} / \rho \cdot g \times 6(1-\varepsilon) \cdot L / D \cdot \phi \cdot \varepsilon^{3} \quad \ldots \ldots \ldots \ldots(1)
$$

where $\Delta P$ : pressure drop

$f$ : friction factor

$G$ : superficial mass velocity



Fig. 1 Change of iron production during experimental operations 


$$
\begin{array}{lrr}
\rho: & \mathrm{kg} / \mathrm{m}^{2} / \mathrm{sec} . \\
g: & \mathrm{kg} / \mathrm{m}^{3} \\
& & \\
D: & \text { meansity of gas } & 9.8 \mathrm{~m} / \mathrm{sec}^{2} \\
L: & \text { height of stock column } & \mathrm{m} . \\
\phi: & \text { sphericity factor } \\
\varepsilon: & \text { free volume coefficient }
\end{array}
$$

The equation (1) is modified as follows:

$$
f \cdot(1-\varepsilon) \varepsilon^{3}=\Delta P \cdot \rho \cdot g \cdot D \cdot \phi / 6 G^{2} \cdot L \quad \cdots \cdots \cdots \cdots(2)
$$

The factor $\varepsilon$ is unknown, so the authors define

$$
f \cdot(1-\varepsilon) / \varepsilon^{3}(=F)
$$

as a modified friction factor. Each term in equation (2) is calculated as follows:

$\Delta P$ : blast pressure-top pressure

$G$ : (blast volume)/(mean section area of iurnace )

$L$ : the height from the stock-line to the tuyere level

$\phi: 1$ (assumed)

This modified friction factor $F$ indicates the permeability of the stock column and is affected by the characteristics of each furnace and the absence of burdens.

Fig. 2 shows the change of $F$ during the experimental operations. $F$ decreased when increasing the sinter ratio in burdens and reached minimum at 100 per cent sinter burden. The reason for this improvement is considered to be that the gasflow resistance of the solid burdens at the upper stack is decreased by the uniformity of the distribution of 100 per cent sinter burden and the primary slag reaction is performed in the sintering process. When the ordinary iron ore burden is used, sticky and high basicity slag is formed at the melting zone. Thus more blast volume and iron production are possible when using 100 per cent A-sinter.



Fig. 2 Change of " $F$ " during experimental operations
Technical Research Institute of Yawata Iron Works investigated this point with an experimental blast furnace by use of A-sinter of 100 per cent, 50 per cent and no sinter in burdens respectively. On each burden, the viscosity, melting temperature and basicity of slag and silicon content in sponge iron were measured at levels of the lower stack, belly and bosh. The viscosity of the primary slag of 100 per cent sinter burden is low at each level. But with a low-sinter burden it is increased steeply at the belly.

The slag basicity changes little in the furnace and $\mathrm{SiO}_{2}$ in the slag is reduced only a little until the bosh zone. Consequently, the use of high blast temperature is possible by use of 100 per cent Asinter.

\section{Coke Rates}

(1) Comparison of each operation

The coke rates in each month are as shown in Fig. 3 and correlated to sinter ratios in Fig. 4. As shown in Fig. 3, the coke rate of A-sinter is the lowest. The coke rate is decreased with a curved line as the sinter ratio in burdens is increased. Consequently, the coke rate is reduced

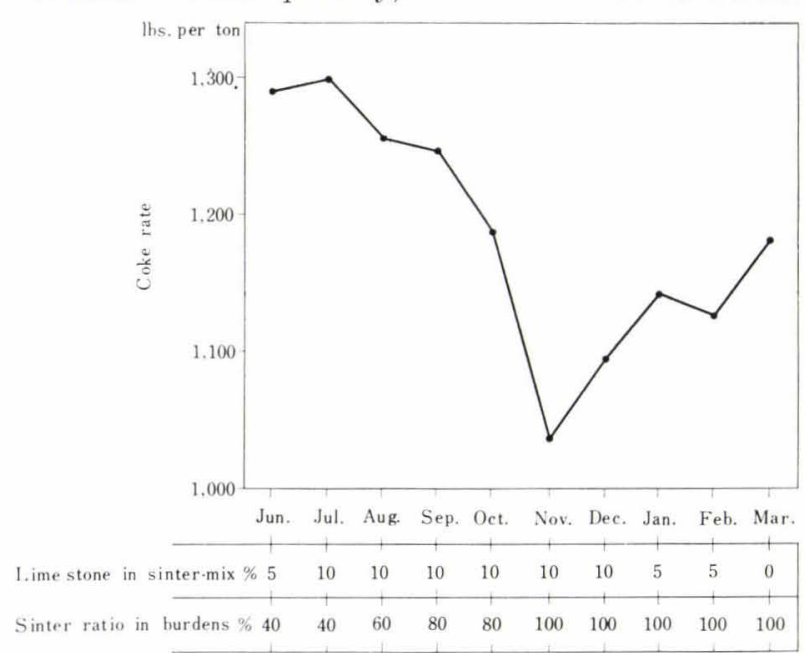

Fig. 3 Change of coke rate

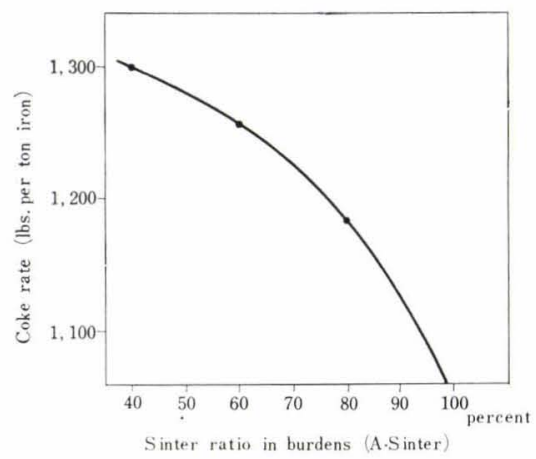

Fig. 4 Relation between coke rate and the sinter ratio 


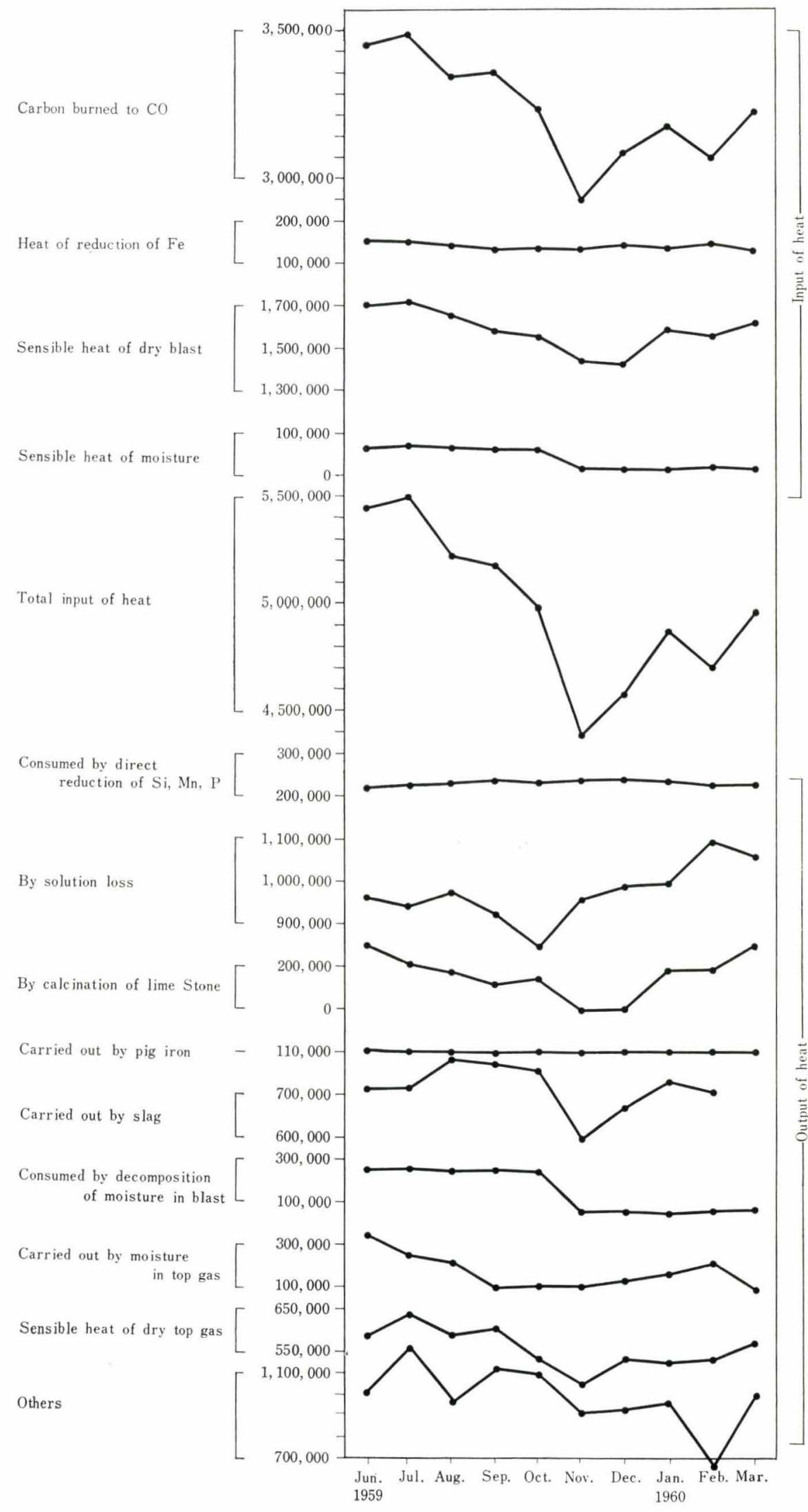


remarkably by the use of over 60 per cent sinter burden.

(2) Discussion on heat balances

The heat balances of each month are as shown in Fig. 5.

The total heat required per ton iron in November 1958 (sinter ratio $=100$ per cent) is about 1,080,000 B.T.U. less than in July 1958 (sinter ratio $=40$ per cent). In November the heat of combustion of carbon was decreased and the sensible heat of the blast was decreased due to decreasing of the blast volume per ton in spite of the use of high blast temperature.

The output of heat will be discussed as follows: (a) Solution loss:

Table $\mathrm{V}$ shows the carbon balance of each month. Although the heat comsumption by solution loss changed little, the top gas volume per ton iron and $\mathrm{CO} / \mathrm{CO}_{2}$ ratio in top gas were decreased remarkably in November (100 per cent A-sinter) as shown in Fig. 6. This means a high reducibility of the lime sinter burden.

(b) The heat for calcining of limestone:

During November and December using 100 per cent A-sinter, no limestone was added to burdens and about 288,000 B.T.U. per ton iron was saved. (c) The sensible heat of the molten slag:

The slag volume was decreased remarkably during use of 100 per cent sinter burden, especially in November 1958. This low slag volume was caused by decrease of the rates of open hearth furnace slag, limestone and coke. The high sinter burden allowed the low basicity operation due to decrease of the input of sulphur, not due to high desulphurization. The saving in heat consumption by low slag volume was considerable. (d) The heat consumed by the decomposition of moisture in blast:

From June to October 1958 the blast was humidified to 15.6 grains per cubic ft. and not humidified after November because the authors found the moisture did not contribute much to the high sinter operation of the blast furnace. Consequently, about 180,000 B.T.U. per ton iron were reduced after November.

(e) Others:

The moisture in the high-sinter burden is so little that the heat carried out by it was reduced. The radiation loss was decreased after November because of high iron production.

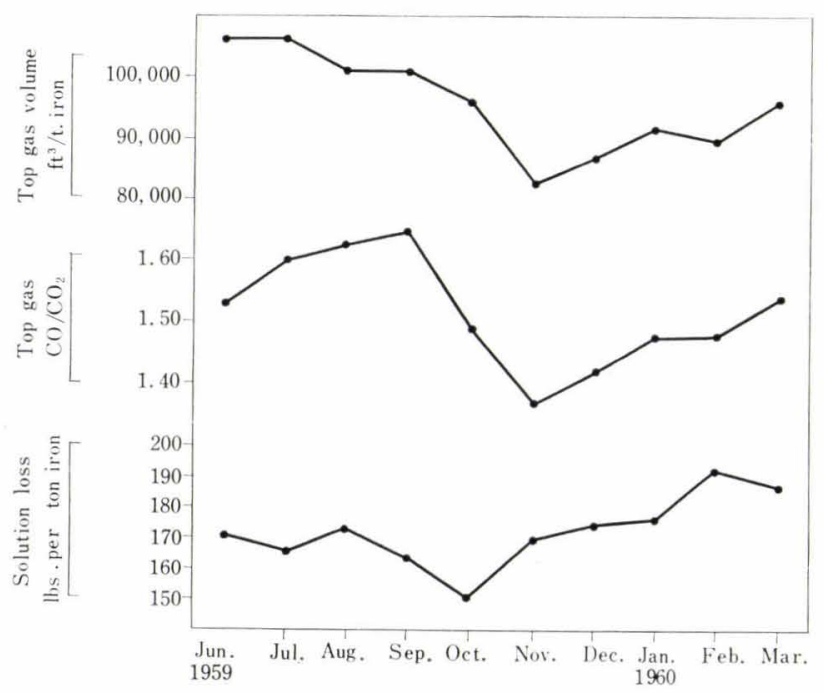

Fig. 6 Top gas volume, $\mathrm{CO} \mathrm{CO}_{2}$ in top gas and solution loss

Table V. Carbon balance of each month

(Unit: lbs per ton iron)

\begin{tabular}{|c|c|c|c|c|c|c|c|c|c|c|c|}
\hline \multicolumn{2}{|r|}{ Year } & \multicolumn{7}{|c|}{1958} & \multicolumn{3}{|c|}{1959} \\
\hline & Month & Jun. & Jul. & Aug. & Sep. & Oct. & Nov. & Dec. & Jan. & Feb. & Mar. \\
\hline \multicolumn{2}{|c|}{ Total carbon gasified in furnace } & 1036.8 & 1045.8 & 1006.2 & 1002.4 & 946.8 & 926.0 & 870.2 & 908.4 & 894.0 & 935.0 \\
\hline \multirow{2}{*}{$\begin{array}{l}\text { Carbon gasified } \\
\text { at tuyeres }\end{array}$} & Consumed by oxygen & 786.4 & 798.0 & 753.4 & 758.6 & 720.4 & 623.0 & 660.8 & 699.2 & 668.2 & 714.8 \\
\hline & Consumed by moisture & 60.2 & 61.2 & 57.8 & 58.2 & 55.2 & 11.4 & 12.6 & 11.0 & 12.4 & 11.6 \\
\hline $\begin{array}{l}\text { Carbon gasified } \\
\text { above tuyeres }\end{array}$ & By direct reduction & 20.6 & 20.8 & 21.6 & 22.2 & 21.4 & 22.2 & 22.6 & 22.4 & 21.2 & 21.4 \\
\hline
\end{tabular}

